\title{
ATUAÇÃO DO ESTADO NOS ABUSOS SEXUAIS NO SISTEMA CARCERÁRIO BRASILEIRO
}

\author{
Mayara Barreto da Silva e Silva ${ }^{1}$
}

RESUMO: Este trabalho tem por objetivo analisar e refletir sobre o papel do Estado perante os abusos sexuais no sistema carcerário brasileiro e seus impactos no apenado, isto é, ponderando um conflito entre normas positivadas e sua real aplicabilidade, avaliando as falhas na administração pública e na legislação. Como metodologia, adotou-se a pesquisa bibliográfica, o método dedutivo e dialético, considerando que os fatos devem ser observados num contexto social. Entre os resultados quanto a prevenção, destacam-se as medidas necessárias para uma mudança significativa do Estado, em conexão com os Direitos Humanos; medidas básicas de precaução para proteger os reclusos, diminuição da precariedade da saúde, educação, psicólogos qualificados e agentes penitenciários preparados. Concluiuse que o sistema prisional brasileiro se encontra em descaso, uma reforma institucional com políticas públicas eficazes, conscientização social humanizada poderia ser uma considerável saída para a modificação adequada, além da diminuição e equilíbrio quanto aos impactos.

Palavras-chave: Sistema Carcerário. Abusos Sexuais. Direitos Fundamentais. Impacto. Prevençã

ABSTRACT: This work intends to analyze the State's actions before sexual abuses in Brazil's prisons and their impacts over the convicted, pointing a conflict between positive laws and their real applicability, considering flaws both in public administration and legislation. Bibliographical research were used as methodology; The deductive and dialectical methods were adopted, since all facts should be seen on a social context. To prevent it, significant changes must occur to the State in order to make it closer to Human Rights, as basic measures to protect inmates, improvements on Healthcare and Education, well prepared psychologists and prison guards. Since brazilian prison system is in neglection, an institutional reform using effective public policies and social awareness could potentially be an exit to an adequate modification, besides reducing and balancing the impacts.

Keywords: Prison. System Sexual. Abuse.Human rights. Impact. Prevent.

\footnotetext{
${ }^{1}$ Graduada em Direito pela Universidade Cândido Mendes - Campos dos Goytacazes e pósgraduada-UNIRIOEAD. E-mail: mayarai8_sf@hotmail.com.
} 


\section{INTRODUÇÃO}

O Estado em relação ao sistema carcerário brasileiro tem deveres e obrigações, no entanto, tem adotado uma postura relapsa quanto a prática que tange os abusos sexuais no cárcere e a proteção dos apenados. Partindo do pressuposto de que todo ser humano é detentor de direitos e garantias mínimas, que deveriam ser asseguradas durante o encarceramento do apenado, tendo como base a legislação e realidade dos apenados brasileiros.

A atuação do estado na ocorrência de abusos sexuais no sistema penitenciário brasileiro tem alcançado visibilidade internacional, devido as precariedades $\mathrm{e}$ condições submetidas aos apenados, que acaba por infringir várias diretrizes de Direitos Humanos e os próprios Direitos Fundamentais da Constituição Brasileira (VERAS, 2010).

Por isso, acredita-se que numa visualização histórica do sistema penitenciário, facilmente constata-se o não cumprimento dos fins a que se destina, isto é, de prevenção e ressocialização. Assim sendo, a atuação do estado, em relação ao cumprimento das legislações de proteção, desrespeita preceitos constitucionais não apoiando nem mesmo após os abusos serem cometidos.

Tendo em vista que a realidade dos apenados brasileiros se encontra em precárias condições, dentro do cárcere ocorre a criação de suas próprias legislações, dando margem para ocorrências de abusos sexuais serem cometidos e sem que haja nenhuma interferência do estado na prevenção (COSTA, 2015).

A ineficácia do estado ao desempenhar seus deveres, traz para o apenado violentado sexualmente, insegurança até para denunciar as autoridades competentes, com isso, acabam convivendo com seus abusadores, cumprindo ordens deles para não serem submetidos novamente aos abusos. 
Há uma preocupação em destacar um aspecto individualizado quanto aos surgimentos desses abusos sexuais, de acordo com os gêneros e possíveis causas sociais que influenciam nos atos, como discriminação de etnia, diversidade sexual e paradigmas sociais.

Portanto, serão analisadas as políticas públicas existentes no ordenamento jurídico e enfatizadas possíveis modificações, tendo como objetivo a diminuição e prevenção dos abusos sexuais cometidos no sistema penitenciário brasileiro. Inicialmente, para alcançar meios adequados de tratamento psicológico para os apenados, sugere-se uma ressocialização, através de trabalho e educação.

\section{ATUAÇÃO DO ESTADO NA PROTEÇÃO DO APENADO}

O sistema penitenciário brasileiro teve uma evolução significativamente lenta, iniciada por ordenações severas e penas variadas, através das Ordenações Afonsinas, Manuelinas e Filipinas. Seus aspectos principais contavam com a violência e a tortura como método de punição, não havendo direito algum sobre o apenado (MACIEL, 2006).

Sendo assim, a privação da liberdade por meio da prisão só se inicia com a nova constituição de 1824 , com o banimento de condutas de violência que visava punir os apenados. Porém, ainda havia a cultura escravista. Somente em 1830 , que se pode visualizar conceitos de justiça e equidade no Código Criminal do Império (SALLA, 2006).

A situação brasileira carcerária é altamente preocupante e destaca uma negligência por parte da sociedade e dos mecanismos de segurança pública. $\mathrm{O}$ ambiente atual é de extrema deterioração, não só as condições de infraestrutura, mas de dignidade humana. Embora, a maior população carcerária, num quadro mais agravante seja do norte-americano, ainda mantém alguns “direitos básicos”, como condições de sobrevivência (MACAULAY, 2006).

A responsabilidade civil, originária do Código Civil, consiste no dever de reparar os danos causados a outrem, sejam eles morais ou patrimoniais, conforme 
preceitua o Art. 927 do Código Civil, “aquele que, por ato ilícito, causar dano a outrem, fica obrigado a repará-lo" (BRASIL, 2002).

Portanto, em razão de um dano patrimonial ou moral causado por seus agentes carcereiros, o Estado pode ser responsabilizado e, consequentemente, deverá reparar a vítima na forma de indenização aos prejuízos causados. Yussef Said Cahali define a responsabilidade civil estatal como uma "obrigação legal que lhe é imposta, de ressarcir os danos causados a terceiros por suas atividades" (CAHALI, 20II).

Observando a responsabilidade do estado no viés objetivo, verifica-se uma conduta, sendo ela por omissão ou ação, praticada pela Administração Pública. Além disso, é destacado que a conduta do agente público deve ocorrer no exercício de suas funções, conforme Cavalieri Filho (2014, p. 280):

Sempre que a condição do agente do Estado tiver contribuído de algum modo para a prática do ato danoso, ainda que simplesmente lhe proporcionando a oportunidade para o comportamento ilícito, responde o Estado pela obrigação ressarcitória. Não se faz mister, portanto, que o exercício da função constitua a causa eficiente do evento danoso; basta que ela ministre a ocasião para praticar-se o ato. A nota constante é a existência de uma relação entre a função pública exercida pelo agente e o fato gerador do dano.

Então, uma simples ausência do agente nas dependências das celas, em pátios, estando o mesmo em seu horário de trabalho, já se configura uma omissão que pode proporcionar violências sexuais nas dependências das penitenciárias, ou quaisquer formas de ação violenta entre os apenados. ${ }^{2}$

Baseado no Art. 5ำ, inciso XLIX da Constituição Federal, "é assegurado aos presos o respeito à integridade física e moral” (BRASIL, I988). Entre vários problemas

\footnotetext{
2 Relatório final de atividades da pesquisa sobre reincidência criminal, conforme Acordo de Cooperação Técnica entre o Conselho Nacional de Justiça (CNJ) e o Ipea (001/2012) e respectivo Plano de Trabalho.
} 
advindos da precariedade do sistema carcerário brasileiro, o mais grave é a morte do detento no sistema prisional.

Levando em consideração todos esses aspectos, concluir que a responsabilidade civil no tocante aos presos é legalmente normativa, e deve ser aplicada, mesmo que diariamente os apenados brasileiros vivam uma realidade de violência e impunidade, seja ela por parte dos agentes penitenciários ou entre eles mesmos. Com isso, é comum a ocorrência de agressões, abusos sexuais, homicídios, espancamentos, extorsões e rebeliões, ajudando no surgimento de um poder paralelo dentro das prisões, que se caracterizam nas facções criminosas, os apenados buscam associação em troca de proteção, invés do estado.

\section{VIOLAÇÃO DOS DIREITOS DOS APENADOS}

A diferença entre o que está positivado na norma e a realidade brasileira é um fato de conhecimento geral. E se tratando do processo carcerário fica ainda mais evidente, tendo em vista, que as garantias mínimas do apenado não são asseguradas conforme legislações positivadas (GARÉ; FARIA, 2018).

De acordo com Rocha (1999), o princípio base para todo e qualquer ser humano, é a dignidade humana, que é um valor inerente a pessoa. Garantida no primeiro artigo da Constituição Brasileira, que não tem havido não tendo eficácias no sistema penitenciário, devido a casos de descaso, abusos e tortura.

Segundo Sarlet (2012, p. 243):

A Constituição Federal de 1988 pode ser considerada como a mais democrática e avançada em nossa história constitucional, seja em virtude do seu processo de elaboração, quanto em função da experiência acumulada em relação aos acontecimentos constitucionais pretéritos, tendo contribuído em muito para assegurar a estabilidade institucional que tem sido experimentada desde então no Brasil.

Além do art. Io, que impõe os princípios fundamentais e fundamentos da República, a Carta Magna em seu art. 5ํㅡㄹ no capítulo I, que dispõe sobre os direitos e 
garantias fundamentais, compunha um rol de 78 incisos, intitulados "Dos Direitos e Deveres Individuais e Coletivos”, que visa garantir direitos a todos os brasileiros, e estrangeiros residentes no País. Assegurando o princípio à vida, à liberdade, à igualdade, à segurança e a propriedade (BRASIL, 1988).

Conforme Ramos (2018), as legislações no decorrer dos anos sofrem distintas modificações, e o que se deve buscar é que possuam uma conformidade maior com os Direitos Humanos. Temos na Declaração Universal dos Direitos do Homem de 1948, a afirmação que o reconhecimento da dignidade inerente a todos os membros da família humana e dos seus direitos iguais e inalienáveis constitui o fundamento da liberdade, da justiça e da paz no mundo.

Essa influência do Direito Internacional dos Direitos Humanos ocorreu no constitucionalismo brasileiro, que adquiriu em seu texto legislativo a Emenda Constitucional no 45, de 2004, que possibilitou a federalização dos crimes contra os direitos humanos, no seu artigo ı09, inciso V, da Constituição Federativa do Brasil:

Art. 109. Aos juízes federais compete processar e julgar:

V - os crimes previstos em tratado ou convenção internacional, quando, iniciada a execução no País, o resultado tenha ou devesse ter ocorrido no estrangeiro, ou reciprocamente;

$\mathrm{V}-\mathrm{A}$ as causas relativas a direitos humanos a que se refere o $\S$ $5^{\circ}$ deste artigo; (Incluído pela Emenda Constitucional no 45 , de 2004)

A criminalidade é uma questão que cada dia mais ganha destaque nos noticiários mundiais e, principalmente, brasileiros. É uma questão de segurança pública, assim como as políticas de segurança devem incluir a administração dos presídios e o tratamento dos reclusos baseados no princípio da dignidade da pessoa humana, não apenas como uma forma de cuidar daqueles que ali estão, mas sim, como forma de prevenção e combate à criminalidade. A naturalidade com que ocorrem as 
violações aos direitos humanos mostra a fragilidade do nosso Estado de Direito ao permitir a prática de violência em nosso país como algo banal, além de não receber a atenção necessária por parte da sociedade e da mídia (PAIVA, 2015).

As cadeias brasileiras não cumprem seu papel de ressocialização tornando, pelo contrário, ainda pior as pessoas que lá entram. A saúde dos presos é comprometida, principalmente pela Síndrome da Imunodeficiência Adquirida (AIDS), adquirido por meio de abusos sexuais e drogas injetáveis presentes nesses locais. As fugas e rebeliões são constantes e mostram a saturação dos encarcerados quanto à situação vivida no cumprimento de suas penas. Os chefes das máfias continuam a comandar internamente após a prisão. A entrada de materiais proibidos, como armas e drogas não consegue ser impedida pelas autoridades responsáveis na maioria dos estabelecimentos. Enfim, temos uma lei regulamentadora que praticamente não existe na prática: apenas subsiste nos códigos como uma meta a ser alcançada distante (PAIVA, 2015).

Conforme Verde (2014) suas pesquisas chamam atenção em relação à interpretação dos brasileiros em relação aos direitos dos presos é o nível de concordância em relação a algumas frases recorrentes no vocabulário popular. Por exemplo, apenas $36 \%$ dos entrevistados discordaram totalmente com a frase "bandido bom é bandido morto", expressão que fere um dos principais direitos humanos apontados pelo mesmo grupo de entrevistados como invioláveis, o direito à vida.

Em virtude dos aspectos observados, o cárcere tem ignorado os direitos humanos, violado em especial o direito à vida. Há negligência estatal, conforme destacado, e uma grande parte de responsabilização de caráter social. O Estado brasileiro está sendo omisso em relação aos encarcerados. O cárcere é sinônimo de esquecimento e abandono estatal.

\section{PREVENÇÃO QUANTO AOS IMPACTOS NOS APENADOS}

Um dos objetivos principais da função do Estado é promover o bem-estar da sociedade. Para tanto, ele necessita desenvolver uma série de ações e atuar diretamente em diferentes áreas, tais como saúde, educação, meio ambiente. Para atingir resultados 
em diversas áreas e promover o bem-estar da sociedade, os governos se utilizam das Políticas Públicas que podem ser definidas como um conjunto de ações e decisões do governo, voltadas para a solução, ou não, de problemas da sociedade (LOPES, 2008).

Conforme Julião (2013), as políticas públicas devem começar investindo principalmente no campo da ressocialização, que necessitam de estudos que contribuam para a constituição de um corpo teórico que possibilite compreender melhor a condição de trabalho e educação para o detento. A educação tem como humanidade seu destaque como garantia de futuro e esperança. Além dos benefícios da instrução escolar e de formação social, o preso pode vir a participar de um processo de modificação de sua visão de mundo, contribuindo para a formação de senso crítico, melhorando o seu comportamento na vida carcerária.

Tem visto que:

A união de esforços dos atores sociais, que podem ser tanto o conselho da comunidade em conjunto com o Poder Judiciário, quanto entidades municipais, é essencial para a recuperação dos apenados, é por meio desta união que será possível a implementação de políticas realmente eficazes. Os inícios a estas ações precisam ser deslanchados, a fim de que cada comunidade consiga comportar e socorrer os apenados de seu território, amenizando, desta forma, as obrigações estatais, bem como o sofrimento dos apenados. As ações e projetos devem trazer a ideia de ressocialização aos apenados visando reduzir os níveis de reincidência, através de medidas que auxiliem na educação, na capacitação profissional e na busca da reinserção na sociedade (DA SILVEIRA, 2013, p. I2)

Para uma efetiva prevenção e diminuição, além de políticas públicas efetivas, que venham a evitar violência e abusos sexuais no cárcere, faz-se necessário, um acompanhamento psicológico para amenizar os impactos causados, mas é preciso considerar que os psicólogos que atuam em prisões podem estar ameaçados caso não 
se proponham a reproduzir a engrenagem da instituição carcerária através de sua atuação. Por outro lado, estes profissionais estão colocados num lugar estratégico no sentido de produzir focos de resistência à rede de poder institucional. Mas para isso ele terão que se desprender de suas atribuições formais e formular outros modos de atuação direcionados no sentido oposto ao da mortificação institucional (RAUTER, 2007).

O Estado tem buscado alternativas para melhorar a condição do preso dentro dos presídios e cadeias públicas de todo país. O Estado tem como função primordial garantir a segurança dentro dos presídios e isso é uma primeira providencia que deve ser tomada para que haja uma mudança da realidade da situação carcerária brasileira, para tanto, deve-se aumentar o efetivo de agentes penitenciários e também o espaço físico nos presídios, já que estes estão sempre superlotados. Assim, algumas estratégias são colocadas buscando melhorar a condição do preso e o fiel cumprimento dos deveres do Estado para com a ressocialização (KUHENE, 2013). Este processo exige um empenho do Estado, uma vez que a sociedade tem que contribuir para a reinserção do preso no convívio social. Greco (2011, p. 443):

Parece-nos que a sociedade não concorda, infelizmente, pelo menos à primeira vista, com a ressocialização do condenado. $\mathrm{O}$ estigma da condenação, carregado pelo egresso, o impede de retornar ao normal convívio em sociedade.

A função do psicólogo lotado em unidades prisionais é a atuação em Comissões Técnicas de Classificação (CTCs) nas quais é decidida a aplicação de punições disciplinares, além de apreciadas solicitações de internos ao longo do cumprimento da pena. A CTC é uma espécie de reunião de equipe interdisciplinar da qual fazem parte agentes penitenciários e técnicos que trabalham numa unidade prisional. Ali são discutidas situações vividas no cárcere sob uma ótica predominantemente disciplinar. De um lado, o preso, posto no lugar de quem comete faltas, infrações, ou na melhor das hipóteses, faz solicitações e do outro, os agentes e técnicos, postos no lugar de quem 
julga, pune, absolve, concede. Ao psicólogo caberia, deste lugar, auxiliar na aplicação dessas medidas disciplinares, uma difícil missão cujos parâmetros ainda estão por ser definidos nos regulamentos oficiais. (RAUTER, 2007).

É importante destacar que existe o atendimento na modalidade plantão psicológico que visa o atendimento individual e de emergência aos presos alocadas na instituição, e tem como objetivos acolher suas demandas emocionais e contribuir para fornecer atenção psicossocial à saúde, auxiliando a traumas pós abusos e violência institucional ou anterior a condenação. Os atendimentos têm como objetivo serem discutidos em supervisão semanal, possibilitando a construção de um banco de dados que continha os relatos clínicos dos atendimentos e das intervenções específicas necessárias a cada caso, porém não é toda instituição carcerária que possui psicólogos especializados e suficientes para a superlotação (GUEDES, 2006).

A saúde também é um dos meios pelos quais podem prevenir impactos quanto aos abusos sexuais, tendo um acompanhamento e tratamento médico especializado, vem sendo observado que os detentos do sexo masculino, em comparação ao sexo feminino, é o mais envolvido em situações de violência, e com o maior índice de reincidência em crimes e consequentemente, no cumprimento prisional. Diante desta problemática, o foco maior é voltado para a SIDA3, a tuberculose ${ }^{4}$, a infecção pelo Vírus da Hepatite B (VHB), e principalmente doenças sexualmente transmitidas (DSTs) 5 , como o Vírus da Imunodeficiência Humana $(\mathrm{HIV})^{6}$, que causa a morte de muitos detentos, com instrumentos necessários para o trabalho, local determinado

\footnotetext{
${ }_{3}^{3}$ Significa Síndrome da Imunodeficiência Humana Adquirida. É um conjunto de sinais e sintomas bem definidos que podem surgir em indivíduos com a infecção pelo Vírus de imunodeficiência humana.

${ }^{4}$ Uma infecção grave do fígado causada pelo vírus da hepatite B, que pode ser facilmente prevenida por meio de vacina, essa doença é transmitida com maior frequência pela exposição a fluidos corporais infectados.

${ }^{5}$ Infecção transmitida por contato sexual, causada por bactérias, vírus ou parasitas.

${ }^{6}$ A AIDS é causada pelo vírus HIV, que interfere na capacidade do organismo de combater infecções, O vírus pode ser transmitido pelo contato com sangue, sêmen ou fluidos vaginais infectados, geralmente advém de relações sexuais consentidas ou não.
} 
dentro da instituição, remédios, seria facilitado o atendimento digno e laudos mais definidos (GOIS, 2012).

A segurança institucional também deve respeitar mais as legislações vigentes, deixando de lado paradigmas sociais, e agindo em confronto com os presos, impondo seus poderes de forma coerente. Para isso, é necessário que os agentes penitenciários tenham mais recursos, especializações e preparo tanto antes do ingresso na carreira, quanto durante seu exercício, para manter um ato contínuo de preparação e modificação de meios para diminuir as violências e abusos cometidos no cárcere (DE MORAES, 2013).

Dessa forma, para a máquina prisional funcionar e que possa ser um meio transformador no sentido de propor outros direcionamentos éticos e políticos para a conflitividade social em nosso país, somente com o aumento de educação, trabalho, saúde, segurança institucional preparada, para diminuir os impactos causados aos apenados, e a toda massa carcerária.

\section{CONCLUSÃO}

Diante do exposto, conclui-se que o sistema carcerário brasileiro perante casos de abusos sexuais encontra-se em profundo descontrole estatal. Tal afirmação, é observada diante dos apenados brasileiros que se encontram vivendo uma realidade paralela as normas positivadas, podendo ser confirmada a partir das análises apresentadas.

No sistema penitenciário brasileiro, pode se destacar que os abusos sexuais ocorrem por motivos distintos a cada indivíduo, tendo visto, que os paradigmas sociais, preconceitos e todo contexto de ineficácia estatal contribuem, dificultando a proteção.

Ficou demonstrado que essa negligência estatal é o que alimenta a crise, pois não há preocupação com a melhora das condições, sendo visto, que após o cometimento dos abusos não há psicólogos preparados para diminuir os impactos causados no apenado, ou médicos especializados para um tratamento digno. Grande parte dos 
problemas apontados podem ser resolvidos através do esforço do Estado, de políticas públicas que incentivem o preso a voltar para a sociedade livre de traumas e vícios que o sistema lhe impregna.

Por fim, é importante ressaltar, o presente trabalho não buscou esgotar o tema, e mesmo assim, é possível constatar violações estatais e impactos exorbitantes aos abusos sexuais cometidos no sistema carcerário brasileiro. Há um longo caminho a ser percorrido até a diminuição e estabilidade do controle estatal. Portanto, através da conscientização social e de investimentos do Poder Público, é possível melhorar os impactos causados nos apenados, trazendo ao cárcere educação, trabalho, saúde e preparo dos agentes penitenciários.

\section{REFERÊNCIAS}

BRASIL, Código Civil Brasileiro, Lei Io.406, de io de janeiro de 2002.

BRASIL. Constituição (1988). Constituição da República Federativa do Brasil. Brasília, DF: Senado Federal: Centro Gráfico, 1988. 292 p. BRASIL.

CAHALI, Yussef Said. Dano Moral. São Paulo: Revista dos Tribunais, 201 .

CAVAliERI FILHO, Sergio. Programa de responsabilidade Civil. II ${ }^{a}$ Edição. São Paulo: Atlas, 20I4.

COSTA. Larissa Aparecida. A Crise Endêmica Do Sistema Carcerário Nacional: Traços

Criminais em Debate. UFERSA-Universidade Federal Rural do Semi-Árido, 2015.

DA SILVEIRA, Simone Ribeiro; AHMAD, Nidal Khalil. ANALISAR A (IN) EFICÁCIA DA PENA PRIVATIVA DE LIBERDADE COMO FORMA DE REABILITAÇÃO DOS APENADOS, 2013. 
DE PAIVA, Bruno Felipe Barboza. A Humanização no Sistema Penitenciário e a aplicação de Tais Principios no Espaço Carcerário. Revista Transgressões Ciências Criminais em Debate. UFERSA - Universidade Federal Rural do Semi-Árido, 2015.

GARÉ; FARIA, 2018 - Caio César Tenório Garé Tatiane Bagagí Faria2. Ano: 2018 DO UNIVEM, V. SEMANA DO CONHECIMENTO. "A TEORIA DO DIREITO PENAL DO INIMIGO COMO UMA AFRONTA AOS PRINCÍPIOS CONSTITUCIONAIS Frei Betto. Cidadania: Educação em Direitos Humanos. Rede Brasileira de Educação em Direitos Humanos, 2I de novembro de 1993.

GRECO, Rogério. Curso de direito penal parte geral. Rio de Janeiro: Impetus, 2013.2 ${ }^{\underline{a}}$ Ed.Rio de Janeiro: Impetus, 2015.

GRECO, Rogério. Direitos Humanos, Sistema Prisional e Alternativa à Privação de histórico-evolutiva. 2. ed. São Paulo: Revista dos Tribunais, 2012. p. 223-246. instrumento de conscientização para a realidade prisional brasileira. Relações Internacionais no Mundo Atual, v. I, n. 19, p. 75-91, 2014.

JULIÃO, Elionaldo Fernandes. Educação e Trabalho como propostas políticas de execução penal. Alfabetização, p. 73, 2006.

KUHENE, Maurício. Lei de Execução Penal Anotada. II. ed. rev. e atual. Curitiba: Jaruá, 2013.

LOPES, Brenner; AMARAL, Jefferson Ney; CALDAS, Ricardo Wahrendorff. Políticas Públicas: conceitos e práticas. Belo Horizonte: Sebrae/MG, v. 7, 2008.

MACAULAY, F. Prisões e política carcerária. In: LIMA, Renato; PAULA, Liana (Orgs.). Segurança pública e violência: o estado está cumprindo o seu papel? São Paulo: Contexto,2006.

MACIEL, JOSÉ FABIO RODRIGUES MACIEL, 2006. 
MARINONI, L. G.; MITIDIERO, D. O Constitucionalismo brasileiro em perspectiva

Prudente: 2018.

RAMOS, André de Carvalho. Teoria geral dos direitos humanos na ordem internacional. Editora Saraiva, 2018.

RAUTER, Cristina. Clínica e estratégias de resistência: perspectivas para o trabalho do psicólogo em prisões. Psicologia e sociedade, v. 19, n. 2,2007.

RAUTER, Cristina. O trabalho do psicólogo em prisões. O Trabalho da (o) psicóloga (o) no sistema prisional: Problematizações, ética e orientações, p. 43-52, 2016.

ROCHA, Cármen Lúcia Antunes. O princípio da dignidade da pessoa humana e a exclusão social. Revista Interesse Público, v. 4, n. 2, p. 23-48, 1999.

SALLA, Fernando. As Prisões em São Paulo ı822-1940.São Paulo: Annablume, 1999.

SARLET, Ingo Wolfgang. Curso de direito constitucional. In: SARLET, I. W.;MARINONI, L. G.; MITIDIERO, D. O Constitucionalismo brasileiro em perspectiva histórico-evolutiva. 2. Ed. São Paulo: Revista dos Tribunais, 2012. P. 223246.

VERAS, Thaísa. O Sistema Nacional de Combate ao Abuso e à Exploração Sexual Infantojuvenil e o Plano Nacional: um exemplo de política pública aplicada. Cad. EBAPE.BR, Rio de Janeiro, v. 8, n. 3, p. 404-421, Sept. 2010.

VERDE, Julianna Villa; ASSUNÇÃO, Thiago. Educação em Direitos Humanos como instrumento de conscientização para a realidade prisional brasileira. Relações Internacionais com no Mundo, v.I, n. 19, p. 75-91,2014. 